\title{
Etiological study of vaginal discharge syndrome in RTI clinic attendees in a tertiary care hospital
}

\author{
S S Tankhiwale, M K Sharma, R B Surpam, S S Fussey \\ Correspondence: Dr. S S Tankhiwale, Associate Professor, Microbiology Department, Govt. \\ Medical College, Nagpur, Maharashtra, India; Email- supriyatankhiwale@yahoo.com \\ Distributed under Creative Commons Attribution-Share Alike 4.0 International.
}

\begin{abstract}
Objective: The aim of the study is to observe the prevalence and the common causes of vulvovaginitis in the reproductive tract infection (RTI) clinic attendees. Methodology: A total of 2342 patients attending RTI clinic in a tertiary hospital in a period of one year were included in the study. Three vaginal swab were collected. Trichomonas vaginalis is diagnosed by wet preparation and culture in kupferberg medium. Bacterial vaginosis is diagnosed according to nugent's criteria. Once growth of Candida is obtained on sabouraud's media, species is identified by conventional method and use of chrome agar medium. Results: Out of 2342 cases, 1053 (44.96\%) cases were confirmed in laboratory means syndromic validations were possible in $45 \%$ cases. Out of these 1053 cases bacterial vaginosis were seen in 454 (19.38\%), Candida in 567 (24.2\%) and Trichomonas vaginalis in 32(1.3\%) cases. Most common species of Candida were $C$. albicans 275(48.5\%), C. parapsilosis 79 (13.9\%) and C. glabrata 72 (12.6\%). About 101 Candida species were not identified by crome agar so reported as Candida species. Conclusion: Most common cause of vaginitis was candidial infection followed by bacterial vaginosis in RTI clinic attendees.

Keywords: Valvovaginitis, vaginal discharge syndrome, candidiasis, Trichomonas vaginalis,
\end{abstract} bacterial vaginosis.

Sexually transmitted diseases (STDs) are very much prevalent, it is estimated that 340 million new cases occur among adults worldwide. ${ }^{1}$ These conditions are also regarded as an important public health problem for its medical, social and economic implications. Vaginal infection is one of the most common gynecological affections and vaginal discharge is one of the most common reasons for which women seek medical attention. ${ }^{2}$ Vulvo-vaginitis is a usual cause of genital infection in women. Bacterial vaginosis, Candida albicans genital infection and trichomoniasis are considered the main etiologies of vulvo-vaginitis. ${ }^{3}$

Bacterial vaginosis is a dysbiosis, in which a decrease in resident vaginal lactobacilli is associated with a growth of anaerobic polymicrobial flora. ${ }^{4}$ Furthermore; bacterial vaginosis has been associated with increased susceptibility to HIV-AIDS and other STD. ${ }^{5}$

Candidial genital infection is the leading cause of fungal vulvo-vaginitis. Described important risk factors

Received: $9^{\text {th }}$ December 2016. Accepted: $25^{\text {th }}$ March 2017.

Tankhiwale SS, Sharma MK, Surpam RB, Fussey SS. Etiological study of vaginal discharge syndrome in RTI clinic attendees in a tertiary care hospital. The New Indian Journal of OBGYN. 2017; 4(1):50-3 
for Candida genital infection are pregnancy, broadspectrum antibiotic use, diabetes mellitus and immune - deficiency. However, asymptomatic microorganism colonization can occur in 25 to $50 \%$ of the cases. ${ }^{3,6,7}$

Trichomonas vaginitis is often transmitted by sexual intercourse. It is the most common sexually transmitted pathogen, accounting for 180 million infections annually worldwide. ${ }^{8}$ Vulvovaginitis is a common problem in clinical practice and vaginal discharge along with itching, pain etc. are commonest presenting symptoms. Management is often complicated by a long history of inappropriate treatments based on tentative diagnoses after an incomplete diagnostic workup. This study was done to find out the most common causes of vulvovaginitis; their prevalence in the reproductive tract infection (RTI) clinic attendees to establish a diagnosis for proper treatment of patients.

\section{Materials and Method}

A total of 2342 patients attending RTI clinic in a tertiary hospital in a period of one year from January 2015 to December 2015 were included in the study. Vaginal swabs were collected from the patients diagnosed with vaginal discharge syndrome (VDS) in RTI OPDS. Three vaginal swab were collected, one for slide microscopy (Gram's stain and wet preparation) collected in the sterile saline bottle, and second one in Kupferberg's medium for Trichomonas vaginalis and third one on Sabouraud's media for growth of Candida.

Without applying any antiseptics, analgesics or lubricants the specimen is collected while wearing sterile gloves. The speculum is moistened with luke warm water. The sterile vaginal speculum is inserted in the vagina and inspected exocervix. Cleaned the exocervix with a sterile cotton wool swab. Another cotton wool swab is inserted in the vagina and the posterior fornix is swabbed for a few seconds. Collect it immediately in the Kupferberg's medium. Swab is dipped well in the medium. Second vaginal swab is collected for microscopy in sterile normal saline while third swab for culture in Stuart's transport media. The $\mathrm{pH}$ paper then touched to the tip of the vaginal speculum after removing it from the vagina for testing the vaginal $\mathrm{pH}$. Normal adult vagina has an acid $\mathrm{pH}$ of 4.0.-4.5 but in bacterial vaginosis the $\mathrm{pH}$ is raised to 4.5 or more. Swab for microscopy is used for preparation of smear on a clean slide for gram's stain (for bacterial vaginosis and candida) and wet preparation for motility of Trichomonas vaginalis. Bacterial vaginosis is diagnosed according to nugent's criteria. Kufperberg's medium is kept at $37^{\circ} \mathrm{C}$ for incubation at least for one week. Sabouraud's medium is kept at 25 and $37^{\circ} \mathrm{C}$ for incubation. ${ }^{9}$ Once growth of Candida is obtained species is identified by conventional method and use of chrome agar medium. ${ }^{10}$

\section{Results}

In one year, 2342 cases of vaginal discharge syndrome were investigated for etiology. All cases
Table 1: Showing age-wise distribution of cases

\begin{tabular}{llll}
\hline $\begin{array}{l}\text { Sr. } \\
\text { No. }\end{array}$ & $\begin{array}{l}\text { Age in } \\
\text { year }\end{array}$ & Nos & $\%$ \\
\hline 1. & $\leq 19$ & 60 & $2.5 \%$ \\
2. & $20-24$ & 335 & $14.3 \%$ \\
3. & $25-44$ & 1699 & $72.5 \%$ \\
4. & $\geq 45$ & 248 & $10.5 \%$ \\
\hline
\end{tabular}

were from age group 19 to 45 and above ( table 1 ) . Maximum cases were from age group 25 to 44 years $(86.8 \%)$. Out of 2342 cases, 1053
Table 2: Showing etiological distribution of cases

\begin{tabular}{llll}
$\begin{array}{l}\text { Sr. } \\
\text { No. }\end{array}$ & Etiological agents & Number & Percentage \\
\hline 1. & Candida spp. & 567 & $24.2 \%$ \\
2. & Bacterial Vaginosis & 454 & $19.38 \%$ \\
3. & Trichomonas & 32 & $1.3 \%$ \\
\hline
\end{tabular}

Table 3: Showing Distribution of Candida Species

\begin{tabular}{llll}
$\begin{array}{l}\text { Sr. } \\
\text { No. }\end{array}$ & Candida Species & Number & Percentage \\
\hline 1. & C.albicans & 275 & $48.5 \%$ \\
2. & C.parapsillosis & 79 & $13.9 \%$ \\
3. & C.glabrata & 72 & $12.6 \%$ \\
4. & C.krusei & 22 & $3.8 \%$ \\
5. & C. tropicalis & 18 & $3.1 \%$ \\
6. & Other species & 101 & $17.8 \%$ \\
\hline
\end{tabular}

(44.96\%) cases were confirmed in laboratory means syndromic validations were possible in $45 \%$ cases. Out 
of these 1053 cases bacterial vaginosis were seen in 454(19.38\%), Candida in 567(24.2\%) and Trichomonas vaginalis in 32(1.3\%) cases (table2).

Most common species of Candida were C.albicans 275(48.5\%), C. parapsilosis 79 (13.9\%), C.glabrata 72 (12.6\%), C. krusei 22(3.8\%) C. tropicalis 18 (3.1\%) and 101 Candida species were not identified by Crome agar so reported as Candida species (table 3).

\section{Discussion}

We studied the 2342 cases of valvo-vaginitis presenting with vaginal discharge. Laboratory confirmation of etiological agents was done in 1053 $(44.96 \%)$ cases. Byun SW reported slightly higher percentage of confirmation of etiological agent $55.3 \%$ (108/195). ${ }^{11}$ At the other end Narayan Khedkar reported $(54 / 380-14.2 \%)$ a very low percentage of laboratory confirmation of vaginitis cases. ${ }^{12}$ Ana Claudia CC found 16/48(38\%) etiological agents in laboratory confirmation which is less than present study. ${ }^{13}$

Most common cause of vaginitis was candidial infection $567(24.2 \%)$ in present study which was also observed by Ana Claudia CC $(23.8 \%)^{13}$, Narayan Khedkar $(30 \%)^{12}$ whereas Byun $\mathrm{SW}^{11}$ found bacterial vaginosis $(37.87 \%)$ to be the commonest cause of vaginitis followed by Candida $(14.87 \%)$. Similarly Rita Elizabeth has found the $22 \%$ candidial infection in adolescents from Salvador followed by bacterial vaginosis $20 \% .{ }^{14}$ Most common candida species in the present study was C. albicans $(48.5 \%)$ followed by C. Parapsillosis (13.9\%), C.glabrata (12.6\%). C.krusei and C.tropicalis were also isolated in lesser percentages (3.8\% \& 3\%). Narayan Khedkar also found C.albicans to be the commonest species (54.5\%) followed by other non albicans Candida (NAC 45.5\%). NAC include C. glabrata, C. tropicalis \& C. krusei. Ana Claudia CC reported C. albicans (40.67\%), C. glabrata (31.2\%), C. parapsilosis (18.8\%) \& C. tropicalis $(9.4 \%)$. These facts show that after $C$. albicans, C. glabrata C. parapsilosis and C. tropicalis are most common species isolated from vulvovaginitis.

Third important etiological agent of vulvovaginitis is Trichomonas vaginalis. In present study only 32
(1.3\%) cases were positive for $T$. vaginalis. Other studies also showed the similar findings. Ana Claudia CC did not found a single case of Trichomonas vaginalis in vulvovaginitis patient. Narayan Khedkar observed $1.8 \%$ cases of Trichomonas vaginalis in infectious vaginitis cases almost similar to present study.

A study on data from the 1960's through to the 1990's demonstrated that there has been a decrease in the frequency of cervicovaginal infection due to Trichomonas vaginalis and an increase in vulvovaginatis due to Candida species especially over the last decade. ${ }^{15}$ Vulvovaginitiis an important public health problem, not only due to the gynecological and obstetric complications associated with it but also because the inflammation of the vaginal mucosa and the reduction of lactobacilli could facilitate the transmission of STDs, especially HIV infection ${ }^{3,6}$. The results obtained demonstrated the high prevalence of genital candidiasis followed by bacterial vaginosis in RTI clinic attendees. Low prevalence of Trichomonas vaginalis is observed in this region. These conditions if undiagnosed or untreated may lead to major obstetric and gyneacological complication which considerably increase treatment cost and hospitalization. Also have a negative impact on female mortality rates.

\section{Conclusion}

The results obtained demonstrated the high prevalence of genital candidias is followed by bacterial vaginosis in RTI clinic attendees. Low prevalence of Trichomonas vaginalis is observed in this region. These conditions if undiagnosed or untreated may lead to major obstetric and gyneacological complication which considerably increase treatment cost and hospitalization.

\section{Acknowledgment}

The authors acknowledge National AIDS Control Organisation (NACO), New Delhi and Maharashtra State AIDS Control Society, Mumbai for financial support. We are thankful to Mrs. Kalindi Deogade for technical support.

Conflict of interest: None. Disclaimer: Nil. 


\section{References}

1.World Health Organization; Global prevalence and incidence of selected curable sexually transmitted infections: overview and estimates. Geneva, 2001. Available at: http:// www. Who .int /hiv/pub /sti/ who_hiv_aids_2001.02.pdf

2.Wang J. Bacterial vaginosis. Primary Care Update for Ob/Gyns. 2000; 7(5): 181-85, 2000.

3.Syed TS, Braverman PK. Vaginitis in adolescents. Adolescent Medicine Clinics. 2004; 15(2): 235-51.

4.Verstraelen H. Verhelst R. Vaneechoutte M,

Temmerman M. The epidemiology of bacterial vaginosis in relation to sexual behavior. BMC Infectious Diseases. 2010; 10(1): article 81.

5.Morris M. Nicoll A. Simms I. Wilson J, Catchpole M. Bacterial vaginosis: a public health review. BJOG. 2001; 108(5): 439-50.

6.Geiger AM, Foxman B, Gillespie BW. The epidemiology of vulvovaginal candidiasis among university students. American Journal of Public Health. 1995; 85(8): 1146-48.

7.Trama JP, Adelson ME, Raphaelli I, Stemmer SM, Mordechai E. Detection of Candida species in vaginal samples in a clinical laboratory setting. Infectious Diseases in Obstetrics and Gynecology. 2005; 13(2): 6367.

8.Kent HL. Epidemiology of vaginitis. American Journal of Obstetrics and Gynecology. 1991; 165(4): 1168-76.

9.National AIDS Control Organization. Standard Operative Procedures forlaboratory investigations in diagnosis of STI/RTIs. New Delhi: NACO, Ministry of Health and Family welfare, Government of India; 2013.

10.Baradkar VP, Mathur M, Kumar S, et al. Hichrome Candida agar for identification of Candida species. Indian J. of Pathology \& Microbiology. 2010; 53(1); 93-95.
11.Byun SW, Park YJ, Hur SY. Affirm VPIII microbial identification test can be used to detect gardnerella vaginalis, Candida albicans and trichomonas vaginalis microbial infections in Korean women. J Obstet Gynaecol Res. 2016; 42(4); 422-6.doi;10.1111/jog.12913.Epub 2016 Jan 20

12.Narayankhedkar A, Hodiwala A, Mane A.

Clinicoetiological Characterization of Infectious Vaginitis amongst Women of Reproductive Age Group feom Navi Mumbai,India. J Sex Transm Dis. 2015:817092. Doi :10.1155/2015/817092. Epub 2015 Aug 17.

13.Claudia CCA, Freitas-Junior R, Ribeiro LFJ, Paulinelli RR, Reis C. Prevalence of vulvovaginitis and bacterial vaginosis in patients with koilocytosis. Sao Paulo Med. J. 2008; 126(6): 333-6.

14.Mascarenhas REM, Machado MSC, Borges da Costa e Silva BF,1 Rodrigo Fernandes, et al. Population of Sexually Active Adolescents from Salvador. Infectious Diseases in Obstetrics and Gynecology. 2012; Article ID 378640, 6 pages. http://dx.doi.org/10.1155/2012/378640

15.Adad SJ, de Lima RV, Sawan ZT, et al. Frequency of Trichomoanas vaginalis, Candida sp. and Gardnerella vaginalis in cervical-vaginal smears in four different decades. Sao Paulo Med J. 2001; 119(6): 200-5.

\section{S S Tankhiwale', M K Sharma², R B Surpam³, S S Fussey ${ }^{4}$}

1Associate Professor, Department of Microbiology, Government Medical College, Nagpur; ${ }^{2}$ Research officer, Microbiologist, GMC, Nagpur; ${ }^{3}$ Microbiology, Govt. Med. College, Nagpur; ${ }^{4}$ Gynaecologist, Govt. Med. College, Nagpur, Maharashtra, India. 